of the Chamaesiphonaceae, but apparently not on the Chroococcaceae. The classification is said to be that of Fritsch (1945). Likewise, although the author states that the classification of the larger taxa of the Chlorophyceae in this work follows that of Fritsch (1935), this is not strictly so, but is modified, as Chapman has himself advocated in other papers. Five families, the Ulotrichaceae, Monostromacea $\theta$, Ulvaceae, Caposiphonaceae and Prasiolaceae, are included in the Ulotrichales. The Siphonocladales also has not the same limits as the Cladophorales in Fritsch's book of 1935. However, this is not the place to digress into questions of the much-debated classification of the Chlorophyceae ; but it is perhaps opportune to emphasize that the existing classificatory systems rest primarily on the comparative morphology of the adult thalli and that there is need that this should be supplemented by intensive studies of developmental morphology and lifehistories. As for the sinaller taxa, the Chlorophyceas includes some genera which are notoriously difficult, such as Ulva, Enteromorpha and Cladophora, genera which would provide suitable material for investigation by one of the modern methods of taxonomic treatment such as have been used successfully for 'difficult' genera of higher plants. Here they are classed as species, varieties and forms; but in the case of Enteromorpha, Chapman uses "ecad" as a taxonomic term. This may indicate his views on the cause of variability in this genus ; but its use here is valueless as well as illegitimate.

Kathleen M. Drew

\title{
AGRICULTURAL RESEARCH AT THE SUDAN CENTRAL RAINLANDS STATION, 1952-56
}

\author{
By Dr. A. H. BUNTING* \\ Recently Senior Research Officer, Sudan Ministry of Agriculture
}

$\mathrm{T}$ HE clay plains of the eastern Sudan occupy many thousands of square miles under normal annual rainfalls of $500-800 \mathrm{~mm}$. In 1952 , following several years of experience of partly mechanized sorghum production in part of the region, the Research Division of the Sudan Ministry of Agriculture opened the Central Rainlands Research Station (Tozi Research Farm) to explore its wider potentialities. Tozi is about a hundred miles south of Sennar and eight miles west of the Blue Nile (lat. $12^{\circ} 30^{\prime} \mathrm{N}$., long. $34^{\circ} 00^{\prime}$ E. approximately). The fifth season of farming and research is now in progress on about 1,300 acres, while housing and essential services have been produced for a community of several hundred, and simple offices and laboratories have been built and partly equipped. The senior staff has fluctuated from three to eight. This article records the more significant results and indications of the work so far.

The programme has been based on the study of crops in the field. About 1,700 rows and plots of a wide range of crops and varieties were grown in 1952 for observation and selection. American cotton, sorghum, groundnuts, sesame and safflower (and more recently maize) appear best suited to the conditions. In 1953 simple and separate trials were used for locating the critical ranges of crop population, planting date and fertilizer nitrogen-level in the main crops, and bulk production, mechanized so far as possible, occupied about 1,000 acres. In the third season somewhat complex multifactorial experiments were introduced to unravel the interrelations of crop population, nitrogen-level, varietal type and sowing date. Around this central agronomic core, soil, plant protection, breeding and other specialist studies have developed. Results, indications and even speculations from research and production are co-ordinated to guide the field-cropping programme each season, so that progress is by successive approximation. Conversely, an annual analysis of field-scale results opens up new lines for research.

- Present address: The University, Reading, Berks.

\section{The Environment}

Over four seasons the rainfall has averaged 680 mm., against a probable normal value of around $700 \mathrm{~mm}$. (about $27 \frac{1}{2}$ in.), mostly rcceived during June-October. Part of it falls in cyclonic storms, the intensity of which has varied seasonally. During July-September the temperatures are buffered around $30^{\circ}$ C. maximum, $20^{\circ}$ C. minimum, with dew points around $20^{\circ} \mathrm{C}$. In late October the southerly transit of the intertropical front suddenly brings in dry air and markedly increases evaporation-rates. The dry season (November-May) is long and hot (up to $44^{\circ}$ C. max.), though the winter nights (December and January) are cool.

The vegetation is an Acacia spp. (largely $A$. seyal), open woodland with tall grass, 10-15 ft. high, with areas of open grassland of various types. The grasses are almost all upright annuals, burnt off each year by fierce bush fires. The stringent ecological conditions restrict the number of plant species to about three hundred; most of the important forms are legumes. Methods for ecological land-use selection have been broadly determined.

\section{Soils and Water Relations}

The soils are formed from deep unleached, alkaline alluvial clays, and have about 70 per cent montmorillonitic clay content and $p \mathrm{H} 8 \cdot 5-9 \cdot 0$. They are fully plastic at field-capacity and crack heavily on drying, while the top few inches fall to a friable mulch. Their colour and extent of base accumulation (but not their content of clay, nitrogen or organic matter, which is less than 1 per cent under natural vegetation) are related to slight topographic differences : lower sites are darker and more alkaline, with more salts and calcium carbonate.

There is no permanent water-table in the soils. After the rains they are dried to wilting point (20-25 per cent moisture on dry weight or less) by transpiration or evaporation. In the new season, water 
enters, at first down the cracks and then by bulk penetration with a defined front. The ultimate depth of penetration depends on the current balance between percolation and evapo-transpiration, which in turn depends on the seasonal rainfall pattern. The penetration in undisturbed bush, where transpiration starts soon after the first showers, seems generally less than in cropped fields sown a few weeks later. Concentrated rainfall can lead to serious local flooding on unplanted land, so that permanent surface drainage systems may prove essential.

Since crop roots do not enter the physiologically dry soil below the water front, the depth of soil exploited for nutrients and water also depends in part on the rainfall pattern, as well as on the root behaviour of particular crops or varieties. 'This broadens considerably the concept of soil fertility. Though nitrogen is the only nutrient to which responses are regularly obtained, they have been economic so far only in groundnuts and maize. Cotton and safflower, the growth of which at Tozi is primarily restricted by water shortage, do not respond, and sorghum and sesame are intermediate. The response in groundnuts perhaps reflects the relatively late stage of the crop's short life (90-95 days at Tozi) at which nitrogen becomes available from the numerous, large and apparently effective nodules. Important phosphate effects have been seen only in maize, while potash improves leaf appearance in Virginia tobacco. Zine is important (together with nitrogen and phosphorus, though the interactions have yet to be worked out) only for maize; but this appears to be more a question of poor root penetration than of a soil deficiency in the conventional sense. No doubt if humus were more abundant, trace element shortages would be more frequent.

Crop sequence experiments were started in 1952 using a two-year design measuring residual effects of crops, fallows and fertilizer nitrogen. Many of the effects can be interpreted conventionally in terms of nitrogen or water relationships. Maize and sesame do not penetrate the soil far enough to use all the available water, so that some accumulates. Bare fallowing checks subsequent crops, even if the stored water is removed with late-sown safflower; but striking benefits of half-fallowing have been seen.

\section{Crop Breeding and Agronomy}

A collection of nearly a thousand local and introduced varieties of sorghum is maintained at 'Cozi. Three high-yielding combine varieties, selected from indigenous material, are being grown on a field-scale in 1956. The optimal population ranges and planting dates are found to be respectively higher and earlier than has been usual in the past, with the result that yields of 2,500-3,500 lb./acre are common in experiments, while 79 acres of bulk production in rotation averaged 2,200 lb./acre in 1955 .

The highest-yielding cotton varieties tested have been the Sudan-bred blackarm resistant BAR. 7/8.1 and BAR. 7/8.2. Early sowing (June) and high population (more than 30,000 plants/acre) have given experimental yields of $1,500 \mathrm{lb}$. seed cotton/acre and more; field-production in 1955 averaged about 1,170 lb./acre on 86 acres, and a small area, about a third of an acre, following an accidental half-fallow, yielded at the rate of $2,200 \mathrm{lb}$./acre.

More than 250 uniform, classified varieties ${ }^{2}$ of groundnuts are maintained. The upright bunch variety, Barberton, established for several years in the Sudan, has hitherto proved the best ; but progeny testing has now given similar experimental yields from the newly introduced Natal Common. Yields of 1,500 lb. kernels/acre are quite common, and well over a ton has been harvested, in experiments, while field yields averaged $900 \mathrm{lb}$./acre on 106 acres in 1955. High populations $(60-80,000$ plants/acr $\theta)$ and timely harvesting are essential.

Breeding programmes in sesame aim at transferring the Venezuelan indehiscence, and the early and profuse flowering of certain American types, to the local material, which is at present used in field. production. Root penetration is relatively poor, and the crop is sensitive to drought in its later stages. While experimental yields have reached $1,200 \mathrm{lb}$./acre of seed, the general run is similar to the field-yields at 500-700 lb./acre.

Safflower, a crop extremely resistant to drought, is sown late after a summer fallow, to mature on stored moisture. Yields are unaffected by fertilizer or variations in population. Selection is aimed at the production of early and profusely flowering upright types. Field yields are $400-500 \mathrm{lb}$./acre only, although in experiments up to $1,200 \mathrm{lb}$./acre has been realized.

'The work on maize nutrition at Tozi (see above) permitted the production of this erop on the clay plains for the first time in 1955. Introduced varieties including hybrids yielded $3,000-3,800 \mathrm{lb}$./acre in preliminary observation plots and rows; local Sudan material (from recent riverain silts) gave $2,000 \mathrm{lb}$./acre on 6 acres.

Minor crops studied include deccan hemp (kenaf), sunflower (where some progress seems to have been made in concentrating a self-fertilizing character), soya bean and Virginia tobacco. The local perennials Rhodes grass (Chloris gayana) and Clitoria ternatea (a prostrate legume) seem likely to be useful, perhaps in mixture, in sown pastures.

\section{Crop Protection and Farming Practice}

Though many potential sources of trouble, including stainers, bollworms, grasshoppers, stemborers and the Puccinia polysora rust of maize, have been recorded, no serious attacks of pests or disease have so far occurred at Tozi. Rosette disease of groundnuts is absent from the region, and the cotton varieties in use are sufficiently resistant to blackarm. Soil-borne diseases and pests of the seed-bed make it essential to use combined insecticidal and fungicidal seed dressings for sorghum and groundnuts, and for the latter a soil dressing of $1 \mathrm{lb}$./acre of dieldrin is standard practice and helps to control thrips and termites.

All land preparation, sowing, inter-row cultivation, ridging and field spraying are mechanized, though on a heavy clay soil under tropical rainfall a high degree of farming skill is necessary to use machinery efficiently. Sorghum and safflower are combined. Groundnuts can be harvested, threshed and decorticated mechanically, but so far the operations are slow and require very careful timing and organization. Cotton and sesame are harvested by hand at present. Tractor-hour records suggest that all the main crops, and particularly cotton and sorghum, are economic at the present levels of field-yield.

${ }^{1}$ Sudan Government, Ministry of Agriculture, 1954. Working Party's Report on the Mechanical Crop Production Scheme. Rotaprint. Pp. iv $+48+22$ diagrams.

2 Bunting, A. H., Emp. J. Exp. Agric., 23, 158 (1955). 